\title{
A comparative study of oral Ketoconazole versus Itraconazole in the treatment of Tinea versicolor
}

\author{
Begum $\mathrm{S}^{1}$, Karim $\mathrm{MN}^{2}$, Haque $\mathrm{AKMR}^{3}$, Rahat MLR ${ }^{4}$
}

\begin{abstract}
Tinea (pityriasis) versicolor is a superficial fungal infection and one of the most commonly found pigmentary disorders of the skin caused by the yeast Malassezia. Multiple topical as well as systemic therapies are available for treatment. Systemic therapies are used for extensive disease, frequent relapse or where topical agents have failed. The aim that translates the rationale of the study was to compare the efficacy, safety, tolerability and cost effectiveness of oral ketoconazole dose $200 \mathrm{mg}$ daily for 7 days versus a single dose of 400 $\mathrm{mg}$ of itraconazole in the treatment of tinea versicolor. A total of 64 patients (aged 18-50 years) were selected for the study from the period of June 2019 to November 2019 in the Department of Dermatology and Venereology, Bangabandhu Sheikh Mujib Medical University, Bangladesh. Cases having extensive involvement were diagnosed clinically and confirmed by wood's lamp and $\mathrm{KOH}$ microscopy was taken. Patients were randomly allocated into equal groups. Group A was given oral ketoconazole dose $200 \mathrm{mg}$ daily for 7 days and Group B has given a single dose of $400 \mathrm{mg}$ of itraconazole. $47(73.4 \%)$ male and $17(26.6 \%)$ female were included in the study. The mean age of group A was 29.2(SD \pm 8.6$)$ and in group $B$ 28.2(SD \pm 8.5$)$ years. The mean duration of the disease in group $A$ was $3.9( \pm 2.7)$ months and $3.5( \pm 2.2)$ months in group B. In group A clinical responders was found cure $25(78.1 \%)$, improvement $5(15.6 \%)$ and failure in $2(6.2 \%)$ and in group $B$ it was found cure $22(68.8 \%)$, improvement $7(21.87 \%)$ and failure $3(9.4 \%)$ at one month. At two months in the group A clinical responder was found to cure $22(68.8 \%)$, improvement $5(15.6 \%)$, failure in $3(9.4 \%)$ and relapse $2(6.2 \%)$. In group B it was found cure 18(56.2\%), improvement $6(18.75 \%)$, failure $4(12.5 \%)$ and relapse $4(12.5 \%)$. Both oral ketoconazole dose $200 \mathrm{mg}$ daily for 7 days versus single dose $400 \mathrm{mg}$ of itraconazole can be effective in the treatment of tinea versicolor with extensive involvement.
\end{abstract}

Key words: Tinea versicolor, Ketoconazole, Itraconazole

CBMJ 2020 July: vol. 09 no. 02 P: 26-33

\section{Introduction}

Tinea versicolor (TV) also known as pityriasis versicolor, is a chronic and benign superficial fungal skin infection caused by Malassezia yeasts. Tinea versicolor is most commonly a disease of teenagers and young adults. $^{1-3}$ Because of the lipid requirements of Malassezia, the yeasts are rarely found on the skin of young children and older individuals but are usually present during the years when sebum production is highest. $^{4,5}$ Tinea versicolor is not contagious; rather, it is an endogenous opportunistic infection. ${ }^{1}$ Diagnosis can be made clinically and confirmed by Wood's light and mycological examination. 6,7 Tinea $^{6}$ versicolor occurs worldwide, but the highest incidence is found in tropical climates. ${ }^{8}$ Tinea versicolor occurs more frequently in areas with higher temperatures and higher relative humidities. ${ }^{9}$ The national prevalence of this condition is $2-8 \%$ of the population in some series. A high rate of the recurrence, reaching as much as $60 \%$ in 1 year and $80 \%$ in 2 years, is an important consideration in Tinea versicolor. ${ }^{10}$ In immunocompetent individuals, factors

1. Dr. Sharmin Begum, Medical Officer, Department of Dermatology and Venereology, BSMMU.

2. Dr. Md. Nazmul Karim, Additional Director, $B S M M U$

3. Dr. AKM Rejaul Haque, Associate Professor, Department of Dermatology and Venereology, BSMMU.

4. Dr. Mohammad Lutfur Rahman Rahat, Medical Officer, Central Skin and Social welfare center, Agrabad, Chittagong.

Address of correspondence:

Email:karimnazmul16@gmail.com

Mobile: : 01711592838 
predisposing to recurrence may be difficult to eradicate, including a tendency toward seborrhea and heavy sweating in the presence of high temperature and high humidity. ${ }^{11}$ There may be an inherited predisposition to the disease. A permanent cure may therefore be difficult to achieve, and this may explain the long-term nature of the disease. ${ }^{12,13}$ Tinea versicolor can be successfully treated with various agents such as topical and oral agents. ${ }^{14}$ Sequentially, a preventive treatment regimen may help to prevent recurrence of pityriasis versicolor. ${ }^{15}$ Topical therapies have been used as a prophylactic but patient compliance is lower and no controlled studies have been reported in the literature, to our knowledge. Oral therapy is also effective for tinea versicolor and is often preferred by patient because it is more convenient and less time-consuming. Fluconazole, ketoconazole and itraconazole are the preferred oral agents. ${ }^{16}$ Various dosing regimens have been used. Itraconazole is usually given at $200 \mathrm{mg} / \mathrm{d}$ for 5,7 or 10 days, $400 \mathrm{mg} /$ day for 3 days and $400 \mathrm{mg} /$ day for 1 day. Although various regimes of ketoconazole have been compared with each other, ketoconazole and itraconazole have not been directly compared. Pramiconazole and sertaconazole have also been used in the management of tinea versicolor. ${ }^{17-19}$ The present study was designed to compare the efficacy, safety, tolerability and costeffectiveness of oral ketoconazole dose $200 \mathrm{mg}$ daily for 7 days versus a single dose of $400 \mathrm{mg}$ of itraconazole in the treatment of tinea versicolor.

\section{Methods:}

This was a prospective comparative study conducted in the Department of Dermatology and Venereology, BSMMU from June 2019 to November 2019. Purposive sampling was done. A total of 64 (47 male and 17 female) patients, aged 18 to 50 years were selected randomly \& included in this study. The patients were diagnosed clinically (based on erythema, scaling, pigmentation) and confirmed by
Wood's lamp examination and $\mathrm{KOH}$ microscopy. All patients were divided into group A and group B equally. Written consent for the study was obtained from all patients.

Inclusion criteria: Subjects included those aged 18 to 50 years who had a clinical diagnosis of tinea versicolor confirmed by Wood's lamp examination and $\mathrm{KOH}$ microscopy and who provided written informed consent before inclusion into the trial.

Exclusion criteria: i) Known sensitivity to ketoconazole and itraconazole, ii) Chronic mucocutaneous candidiasis or any serious systemic illness, iii) Immunosuppressant caused by disease or treatment, and iv) Any other disease or condition that in the investigator's opinion should exclude the patient from the trial.

Open active treatment was given $200 \mathrm{mg}$ ketoconazole daily for 7 days in group $A$ and single dose itraconazole $400 \mathrm{mg}$ was given in group B. Patients who fulfilled the inclusion and exclusion criteria at the first visit (baseline) were included in the study.

\section{Results:}

64 cases of tinea versicolor were enrolled. The mean age of the respondents was $28.7( \pm 8.5)$ years. Mean age in group $A$ $29.2( \pm 8.6)$ years and $28.2( \pm 8.5)$ years in group B.

Table 1: Shows the age distribution of the patients $(n=64)$.

\begin{tabular}{|l|c|c|c|c|}
\hline \multirow{2}{*}{ Age } & \multicolumn{3}{|c|}{ Study Group } & \multirow{2}{*}{ P value } \\
\cline { 2 - 4 } & Group $-\mathrm{A}(\mathrm{n}=32)$ & Group $-\mathrm{B}(\mathrm{n}=32)$ & Total $(\mathrm{n}=64)$ & \\
\hline 18-20 years & $8(25.0)$ & $11(34.4)$ & $19(29.7)$ & \\
\hline 21-30 years & $13(40.6)$ & $12(37.5)$ & $25(39.1)$ & \multirow{2}{*}{$p>0.05$} \\
\hline $31-40$ years & $8(25.0)$ & $7(21.9)$ & $15(23.4)$ & \\
\hline 41-50 years & $3(9.4)$ & $2(6.2)$ & $5(7.8)$ & \\
\hline Mean $( \pm \mathrm{SD})$ & $29.2( \pm 8.6)$ & $28.2( \pm 8.5)$ & $28.7( \pm 8.5)$ & $\mathrm{p}>0.05$ \\
\hline
\end{tabular}

' $Z$ test was applied to analyze the data. SD: Standard Deviation. 
Table 2: Distribution of the patients according to sex.

\begin{tabular}{|l|c|c|c|c|}
\hline \multirow{2}{*}{ Sex } & \multicolumn{3}{|c|}{ Study Group } & \multirow{2}{*}{ P value } \\
\cline { 2 - 4 } & Group-A (n=32) & Group-B (n=32) & Total(n=64) & \\
\hline Male & $25(78.1)$ & $22(68.8)$ & $47(73.4)$ & \\
\hline Female & $7(21.9)$ & $10(31.2)$ & $17(26.6)$ & \multirow{2}{*}{$p>0.05$} \\
\hline Total & $32(100.0)$ & $32(100.0)$ & $64(100.0)$ & \\
\hline
\end{tabular}

Table 3: Distribution of the patients according to morphological types of pityriasis versicolor.

\begin{tabular}{|l|c|c|c|c|}
\hline \multirow{2}{*}{ Types } & \multicolumn{3}{|c|}{ Study Group } & \multirow{2}{*}{ value } \\
\cline { 2 - 4 } & Group-A (n=32) & Group-B (n=32) & Total(n=64) & \\
\hline $\begin{array}{l}\text { Hypo } \\
\text { pigmented }\end{array}$ & $26(81.2)$ & $24(75.0)$ & $50(78.1)$ & \\
\hline $\begin{array}{l}\text { Hyper } \\
\text { pigmented }\end{array}$ & $8(18.8)$ & $8(25.0)$ & $14(21.9)$ & \multirow{2}{*}{$>00.05$} \\
\hline Total & $32(100.0)$ & $32(100.0)$ & $64(100.0)$ & \\
\hline
\end{tabular}

Table 4: Distribution of the patients according to the duration of disease.

\begin{tabular}{|l|c|c|c|}
\hline \multirow{2}{*}{ Sex } & \multicolumn{2}{|c|}{ Study Group } & value \\
\cline { 2 - 3 } & $\begin{array}{l}\text { Group-A } \\
(n=32)\end{array}$ & Group-B ( $\mathrm{n}=32)$ & \\
\hline $1-3$ months & $20(62.5)$ & $21(65.62)$ & \\
\hline $4-6$ months & $7(21.9)$ & $5(15.62)$ & \multirow{2}{*}{00.05} \\
\hline $7-9$ months & $3(9.4)$ & $4(12.5)$ & \\
\hline $10-12$ months & $2(6.2)$ & $2(6.2)$ & \\
\hline Mean $( \pm$ SD) & $3.9( \pm 2.7)$ & $3.5( \pm 2.2)$ & $\mathrm{p}>0.05$ \\
\hline
\end{tabular}

Table 5: Distribution of the patients according to clinical response at 1 month.

\begin{tabular}{|l|c|c|l|}
\hline \multirow{2}{*}{ Types } & \multicolumn{2}{|c|}{ Study Group } & \multirow{2}{*}{ P value } \\
\cline { 2 - 3 } & Group-A ( $\mathbf{n}=32)$ & Group-B $(\mathbf{n}=32)$ & \\
\hline Cure & $25(78.1)$ & $22(68.8)$ & \\
\hline Improvement & $5(15.6)$ & $7(21.87)$ & \multirow{2}{*}{$p>0.05$} \\
\hline Failure & $2(6.2)$ & $3(9.4)$ & \\
\hline Total & $32(100.0)$ & $32(100.0)$ & \\
\hline
\end{tabular}

Table 6: Distribution of the patients according to clinical response at 2 months.

\begin{tabular}{|l|c|c|c|}
\hline \multirow{2}{*}{ Types } & \multicolumn{2}{|c|}{ Study Group } & \multirow{2}{*}{ P value } \\
\cline { 2 - 3 } & Group-A ( $\mathbf{n = 3 2 )}$ & Group-B (n=32) & \\
\hline Cure & $22(68.8)$ & $18(56.2)$ & \\
\hline Improvement & $5(15.6)$ & $6(18.75)$ & \\
\hline Failure & $2(6.2)$ & $4(12.5)$ & \multirow{2}{*}{$p>0.05$} \\
\hline Relapse & $2(6.2)$ & $4(12.5)$ & \\
\hline Total & $32(100.0)$ & $32(100.0)$ & \\
\hline
\end{tabular}

Table 7: Distribution of the patients according to mycological response at 1 month.

\begin{tabular}{|c|c|c|c|}
\hline \multirow{2}{*}{$\begin{array}{l}\text { Mycological } \\
\text { response } \\
\text { at } 1 \text { month }\end{array}$} & \multicolumn{2}{|c|}{ Study Group } & \multirow{2}{*}{$P$ value } \\
\hline & Group-A ( $n=32)$ & Group-B $(n=32)$ & \\
\hline Eradication & $26(81.25)$ & $24(75.0)$ & \multirow{3}{*}{$p>0.05$} \\
\hline Persistent & $6(18.75)$ & $8(25.0)$ & \\
\hline Total & $32(100.0)$ & $32(100.0)$ & \\
\hline
\end{tabular}

Table 8: Distribution of the patients according to mycological response at 2 months.

\begin{tabular}{|c|c|c|c|}
\hline $\begin{array}{c}\text { Mycological } \\
\text { response at } \\
\text { 2 months }\end{array}$ & \multicolumn{2}{|c|}{ Study Group } & P value \\
\cline { 2 - 3 } Eradication & $25(78.12)$ & $22(68.75)$ & \\
\hline Persistent & $5(15.62)$ & $7(21.9)$ & \\
\hline $\begin{array}{c}\text { Eradication } \\
\text { with reinfection }\end{array}$ & $2(6.2)$ & $3(9.4)$ & \\
\hline Total & $32(100.0)$ & $32(100.0)$ & \\
\hline
\end{tabular}

Table 9: Distribution of patients by adverse effects.

\begin{tabular}{|l|c|c|l|}
\hline \multirow{2}{*}{$\begin{array}{l}\text { Adverse } \\
\text { effects }\end{array}$} & \multicolumn{2}{|c|}{ Study Group } & \multirow{2}{*}{ P value } \\
\cline { 2 - 3 } & Group- $\mathrm{A}(\mathrm{n}=32)$ & Group-B ( $\mathrm{n}=32)$ & \\
\hline Occurred & $6(18.75)$ & $8(25.0)$ & \\
\hline Not occurred & $26(81.25)$ & $24(75.0)$ & $\mathrm{p}>0.05$ \\
\hline Total & $32(100.0)$ & $32(100.0)$ & \\
\hline
\end{tabular}




\section{Discussion}

Tinea Versicolor may be treated with topical or oral agents, with the latter being used especially when the disease is widespread or does not respond to topical measures. Systemic agents used for treating tinea versicolor include itraconazole, ketoconazole, and itraconazole. ${ }^{4,5}$

Treatment regimens for tineaversicolor consisting of 5,15 or 25 days of ketoconazole ( $200 \mathrm{mg}$ daily) were compared in a blind study. There were no differences in the cure or relapse rates with these treatment regimes. Overall cure rates 6 weeks after therapy ranged from $78 \%$ to $90 \%$. Treatment with a daily $200 \mathrm{mg}$ tablet of ketoconazole for 5 days can be used for most cases of tinea versicolor with longer periods of oral therapy being reserved for resistant cases. Ketoconazole several regimens have been employed for TV. The most common is $200 \mathrm{mg} /$ day for 10 days. ${ }^{10}$

This is a comparative study was conducted in the Department of Dermatology and Venereology, Bangabandhu Sheikh Mujib Medical University, Dhaka during the period from June 2019 to November 2019 to compare the effectiveness of ketoconazole and itraconazole in the treatment of Tinea versicolor. For this purpose, 64 patients with tinea versicolor were selected and divided into group-A and group-B randomly each consisting of 32 patients. Patients of groupA were treated with ketoconazole 200 $\mathrm{mg} /$ day orally for 7 days and group B were treated with itraconazole $400 \mathrm{mg}$ orally single dose after food. The outcome of the study is described below:

The age of the patients ranged from 18 to 50 years with the mean age of 28.7 (SD $\pm 8.5)$ years.

The mean age of patients was 29.2 (SD \pm 8.6 ) years in group- $A$; whereas the age of the patients in group $B$ ranged from 18 to 50 years with the mean age of 28.2 (SD \pm 8.5 ) years. The mean age of the patients of both groups did not show any significant difference [29.2 (SD \pm 8.6$)$ years vs 28.2
(SD \pm 8.5$)$ years; $p>0.05]$. A similar result was observed by Rad et al. study.

They showed a mean age of the patients of tinea versicolor was 26.5 ( $\mathrm{SD} \pm 8.5)$ years, range (15-45 years). This study also showed that among the total 64 patients 25 (39.1.5\%) patients were between 21 to 30 years, $19(29.7 \%)$ patients were between 18 to 20 years, $15(23.4 \%)$ patients were between $31-40$ years and $5(7.8 \%)$ patients were between 41 to 50 years. There was no statistically significant difference in the age group of the patients between the groups ( $p>0.05)$. This result was supported by Rao et al. ${ }^{21}$ that the most affected age group was 21 to 30 years $(30.0 \%)$. A similar finding was also reported by Dutta et al. ${ }^{22}$ (age group: 11 to 30 years). Ghosh et al. ${ }^{23}$ noted the most affected age group was 11 to 20 years $(37.27 \%)$, followed by 21 to 30 years $(32.73 \%)$. In this regards Ahn et al. ${ }^{24}$ found $9(45.0 \%)$ patients were between 20 to 29 years, $5(25.0 \%)$ patients were between 18 to 19 years, $5(25.0 \%)$ patients were between $30-39$ years and $1(5.0 \%)$ patients were between 40 to 49 years.

In this study out of a total 64 patients, $47(73.4 \%)$ patients were male and $17(26.6 \%)$ patients were female with a male to female ratio of $2.76: 1$. The sex of the patients of group A and group B did not show any statistically significant difference ( $p>0.05$ ). This result was by following per study of Rao et al. ${ }^{21}$ that out of the 120 patients examined, $88(73.30 \%)$ were males and $32(26.60 \%)$ were females. A similar result was also observed in the study of Ahn et al. ${ }^{24}$ they showed that $14(70.0 \%)$ patients were male and 6(30.0\%) patients were female with a male to female ratio of 2.33:1. A similar result was found by $\mathrm{Rad}$ et al. ${ }^{20}$ that there were $27(27 \%)$ female and 73 (73\%) male patients. Krishnan et al. ${ }^{25}$ also found a predominance of male patients. In contrast, the present consensus is that both sexes are equally prone to develop tinea versicolor. $^{23}$

In the current study among the total 64 patients, $50(78.1 \%)$ patients had 
hypopigmented and $14(21.9 \%)$ patients had the hyperpigmented type of tinea versicolor. The morphological types of tinea versicolor between the patients of group $A$ and group $B$ did not show any statistically significant difference $(p>0.05)$. This result was in line with the study of Ghosh et al. ${ }^{23}$ that morphologically most lesions were hypopigmented macules (81.83\%), hyperpigmented macules in $14.54 \%$ and mixed types in $3.63 \%$ of patients. Ahn et $\mathrm{al.}^{24}$ also found $14(70.0 \%)$ patients had hypopigmented and $6(30.0 \%)$ patients had hyperpigmented type of tinea versicolor. Rao et al. ${ }^{21}$ also showed a predominance of hypopigmented lesions (75\%). But this result does not corroborate with that of Aljabre et $a l^{25}$ who concluded that tinea versicolor does not tend to be significantly hypopigmented in dark skinned individuals. This variation may probably be due to differences in climates in different study populations.

The duration of disease ranged from 1 to 10 months with the mean duration of $3.9( \pm 2.7)$ months in group- $A$; whereas the duration of disease in group-B ranged from 1 to 12 months with the mean of $3.5( \pm 2.2)$ months. The mean duration of disease of both groups did not show any significant difference $(p>0.05)$. This result was correlated with the study of Rad et al. ${ }^{20}$ that the mean values for disease duration in group 1 and group 2 were $3.09 \pm 0.43$ and $3.61 \pm 0.51$ months respectively. Wahab et al. $^{26}$ also found the mean duration of disease in two groups were $2.63 \pm 2$ months and $2.76 \pm 2$ months respectively.

In this study clinical response was cured in $25(78.1 \%)$, improved in 5(15.6\%) and failure in $2(6.2 \%)$ patients in group-A; whereas clinical response was cured in $22(68.8 \%)$, improved in $7(21.87 \%)$ and failure in $3(9.4 \%)$ patients in group-B. Clinical response at 1 month between the patients of group-A and group-B did not show any statistically significant difference $(p>0.05)$. The overall clinical success (cure plus improvement) was considered, response rates among the treatment groups were comparable [30(93.75\%) vs $29(90.62 \%)]$. Similar results observed in the study of Silva et $a l^{27}$ that at 1-month follow-up cure plus improvement rate was found in 66(90.4\%) and failure in $6(8.2 \%)$ patients treated with ketoconazole; on the other hand cure plus improvement rate was in $67(94.2 \%)$ and failure in $3(4.2 \%)$ patients treated with single dose itraconazole $(p>0.05)$.

The present study showed that clinical response at 2 months the cured rate was $22(68.8 \%)$, Improved in $5(15.6 \%)$, failure in $3(9.4 \%)$ and relapse in $2(6.2 \%)$ patients in group $A$; while the clinical response was cured in $18(56.2 \%)$, improved in $6(18.75 \%)$, failure in $4(12.5 \%)$ and relapse in $4(12.5 \%)$ patients in group-B. Clinical response at 2 months between the patients of group $A$ and group B did not show any statistically significant difference $(p>0.05)$. The overall clinical success (cure plus improvement) was considered, response rates among the treatment groups were comparable [27 $(84.37 \%)$ vs $24(75.0 \%)]$. This result was corroborated with Silva et al. ${ }^{27}$ that at 2month cure plus improvement rate was in $68(94.4 \%)$, failure was in $4(5.6 \%)$ and relapse was in $0(0.0 \%)$ in patients treated with ketoconazole; while cure plus improvement rate was in $62(89.9 \%)$, failure was in $7(10.1 \%)$ and relapse was in $0(0.0 \%)$ patients treated with single dose $400 \mathrm{mg}$ itraconazole $(p>0.05)$. In this regards $\mathrm{Kose}^{28}$, found a clinical cure in $80 \%$ of patients treated with itraconazole. Bhogal et $a^{29}$, found after 4 weeks of treatment clinical cure rate was $80 \%$ with itraconazole $400 \mathrm{mg}$ single dose and $73.3 \%$ with ketoconazole $200 \mathrm{mg}$ for 10 days.

In this study the mycological response at 1 month was eradication in $26(81.25 \%)$ and persistent in $6(18.75 \%)$ patients in group-A; while mycological response was eradication in $24(75.0 \%)$ and persistent in $8(25.0 \%)$ patients in group-B. Mycological response at 1 month between the patients of group-A and group-B did not show any statistically significant difference $(p>0.05)$. These 
findings were in agreement with Silva et al. $^{27}$ that at 1 -month follow-up eradication rate was in $64(88.9 \%)$ and persistent in $7(9.7 \%)$ and reinfection in $1(1.4)$ patients treated with ketoconazole; while eradication rate was in $57(80.3 \%)$, persistent in $10(14.1 \%)$ and eradication with reinfection in $4(5.6 \%)$ patients treated with single dose $400 \mathrm{mg}$ itraconazole $(p>0.05)$. Bhogal et a ${ }^{29}$, found mycological cure rate after 4 weeks of treatment was $82.2 \%$ with itraconazole $400 \mathrm{mg}$ single dose and $73.3 \%$ with ketoconazole $200 \mathrm{mg}$ for 10 days.

This study showed that mycological response at 2 month was eradication in $25(78.12 \%)$, persistent in $5(15.62 \%)$ and eradication with reinfection in $2(6.2 \%)$ patients in group-A; while the mycological response was eradication in $22(68.75 \%)$, persistent in $7(21.9 \%)$ and eradication with reinfection in $3(9.4 \%)$ patients in group-B. Mycological response at 2 month between the patients of group-A and group-B did not show any statistically significant difference $(p>0.05)$. This results was concordant with the study of Silva et al. ${ }^{27}$ found that at 2 month follow-up eradication rate was in $61(84.7 \%)$, persistent in $7(9.7 \%)$ and eradication with reinfection in $4(5.6 \%)$ patients treated with ketoconazole; whereas eradication rate was in $55(78.6 \%)$, persistent in $8(11.4 \%)$ and eradication with reinfection in $7(10.0 \%)$ patients treated with single dose $400 \mathrm{mg}$ itraconazole ( $p>0.05)$. In this regards $\mathrm{Kose}^{28}$, found mycological cure was $88 \%$ in the itraconazole group. Bhogal et $a^{29}$, found mycological cure $82 \%$ with itraconazole and $73 \%$ with ketoconazole (not statistically significant). The relapse rate was $0 \%$ in the itraconazole group and $4 \%$ in the ketoconazole group. Silva et $a /^{27}$, found that mycological cure at day 60 was $78.6 \%$ in itraconazole and $84.7 \%$ in ketoconazole and reinfection at day 60 was $10.0 \%$ initraconazole and $5.6 \%$ in ketoconazole (no significance calculated). Bhogal et $a f^{29}$, found mycological cure rate after 4 weeks of treatment $73.3 \%$ with ketoconazole and $82.2 \%$ with itraconazole. Farschian et $a^{30}$, found that the results of the study showed no significant differences in efficacy, safety and tolerability between ketoconazole and itraconazole and demonstrated similar efficacy in the treatment of tinea versicolor.

Regarding adverse effects, the present study showed that $6(18.75 \%)$ patients of the ketoconazole group and $8(25.0 \%)$ cases of the itraconazole group developed adverse effects during the treatment period $(p>0.05)$. Adverse effects were vertigo (2), nauseavomiting (3) and diarrhoea (1) in the ketoconazole group; while adverse effects were vertigo (5), nausea-vomiting (3) in itraconazole group. But due to these adverse effects discontinuation was not required.

\section{Conclusion:}

This comparative clinical trial shows that ketoconazole $200 \mathrm{mg}$ daily for 7days and itraconazole $400 \mathrm{mg}$ single dose were effective in the treatment of tinea versicolor with almost similar efficacy and safety profile. According to the results of our study, the recurrence rate is lower with ketoconazole than itraconazol (nonsignificant) after the cessation of the therapeutic agents.

\section{References:}

1. Gupta AK, Batra R, Bluhm R, Faergemann $J$ J. Pityriasisversicolor. DermatolClin 2003;21:413-429.

2. Gupta AK, Bluhm $R$, Summerbell $R$. Pityriasis versicolor. J Eur Acad Dermatol Venereol 2002; 16:19-33.

3. Faergemann J. Pityriasis versicolor. Semin Dermatol 1993; 12:276.

4. Robertson LI. Itraconazole in the treatment of widespread tinea versicolor. ClinExpDermatol 1987; 12:178.

5. Schwartz RA. Superficial fungal infections. Lancet 2004; 364:1173. 
6. Robertson LI. Itraconazole in the treatment of widespread tinea versicolor. Clin Exp Dermatol 1987; 12:178.

7. Massone L,Pestarino A, Borghi S, CasiniLemmi $M$, Isol V,Cilli $P$. Oral itraconazole in the treatment of pityriasis versicolor: a comparison of two different dosage regimen. Mycologia Dermatologica. 1991;5:90-2.

8. Silva H, Gibbs D, Arguedas J. A comparison of fluconazole with ketoconazole, itraconazole, and clotrimazole in the treatment of patients with pityriasis versicolor. Current Therapeutic Research. 1998; 59:203.

9. del Palacio Hernanz A, Fras-Iniesta J, Gonzalez-Vale O,Borgers $M$, van Cutsem J, Cauwenbergh $G$. Itraconazole therapy in pityriasis versicolor. $\mathrm{Br} J$ Dermatol. 1986;11:217-25.

10. James WD, Berger TG, Elston DM. Andrews' diseases of the skin: clinical dermatology. 11th ed. Philadelphia, PA: Elsevier; 2011.

11. Borelli $D$, Jacobs $P H$, Nall L. Tinea versicolor: epidemiologic, clinical, and therapeutic aspects. J Am Acad Dermatol. 1991;25:300-305.

12. Faergemann J. Pityriasis versicolor. Semin Dermatol 1993; 12:276.

13. Sunenshine PJ, Schwartz RA, Janniger CK. Tinea versicolor. Int $J$ Dermatol. 1998;37648- 655.

14. Delescluse J. Itraconazole in tinea versicolor: $A$ review. $J A m$ Acad Dermatol.1990;23:551-4.

15. Delescluse J, Cauwenbergh G, Degreef $H$. Itraconazole, a new orally active antifungal in the treatment of pityriasis versicolor. $\mathrm{Br} \mathrm{J}$ Dermatol. 1986;114701- 703.

16. Cuce LC, Belda W. Tibeiro EB. Itracoazole in the treatment of pityriasis versicolor: comparison between 5 and 7 days of treatment. Rev Inst Med Trop Sao Paulo. 1990;32:181-4

17. Van Cutsem J. The in-vitro antifungal spectrum of itraconazole. Mycoses. 1989;32 (suppl 1)
18. Neil $H$. Shear, MD, FRCPC reviewing Faergemann $J$ et al. Arch Dermatol 2002 Jan. Monthly Itraconazole Controls Pityriasis Versicolor,NEJM-Journal Watch.2002 Feb.

19. Hernanz ADP, Frias-Iniesta J, GonzalezValle $O$, Borgers $M$, Van Cutsem J, Cauwenbergh G. Itraconazole therapy in pityriasis versicolor. $\mathrm{Br} J$ Dermatol. 1986;115217- 225.

20. Rad F, Aala F, Reshadmanesh N, Yaghmaie R. Randomized comparative clinical trial of Artemisia Sieberi 5\% lotion and clotrimazole $1 \%$ lotion for the treatment of tinea versicolor. Indian $J$ Dermatol 2008:vol.53(3):pp.115-8.

21. Rao GS, Kuruvilla $M$, Kumar $P$, Vinod $V$. Clinico Epidemiological studies on tinea versicolor. Indian J Dermatol Venereol Leprol 2002;68:208-9.

22. Dutta S, Bajaj AK, Basu S, Dikshit A. Tinea versicolor: Socioeconomic and clinicomycological study in India. Int $\mathrm{J}$ Darmatol 2002;41:823-4.

23. Ghosh SK, Dey SK, Saha I, Barbhuiya JN, Ghosh A, Roy AK. Tinea versicolor: a clinicomycological and epidemiological study from a tertiary care hospital. Indian $J$ Dermatol 2008;53(4):182-5.

24. Ahn KJ, Kim KJ. Yi GJ. Efficacy of one-week regimen of itraconazole for tinea versicolor. Korean J Med Myco11999;4:124-30.

25. Aljabre SH, Alzayir $A A$, Abdulghani $M$, Osman 00. Pigmentary changes of tinea versicolor in dark - skinned patients. Int $J$ Dermatol 2001;40:273-5.

26. Wahab MA, Ali ME, Rahman $M H$, et al. Single dose (400 mg) versus 7 day (200 mg) daily dose itraconazole in the treatment of tinea versicolor: a randomized clinical trial. Mymensingh Med J. 2010;19:72-76.

27. Silva H, Gibbs D, Arguedas J. A comparison of itraconazole with ketoconazole, itraconazole, and clotrimazole in the treatment of patients with tinea versicolor. Curr Ther Res Clin Exp 1998;59(4):203-14

28. Kose 0. Itraconazole versus itraconazole in the treatment of tinea versicolor. Int $J$ Dermatol 1995;34(7):498-9. 
Original Article

29. Bhogal CS, Singal A, Baruah MC. Comparative efficacy of Woconazole and itraconazole in the treatment of tinea versicolor: a one year follow-up study. J Dermatol 2001;28(10):535-9.

30. Farschian $M$; Yaghoobi $R$; Samadi K.Itraconazole versus ketoconazole in the treatment of tinea versicolor.J Dermatolog Treat;2002 Jun;13(2):10-2.PubMed ID: 11930825. 